\title{
Randomized controlled trial comparing outcome of intramedullary nailing versus percutaneous locked plating of extra-articular proximal tibial fractures
}

\author{
P Chaudhary, BP Shrestha, GK Khanal, R Rijal, R Maharjan \\ Department of Orthopaedics \\ B.P. Koirala Institute of Health Sciences, Dharan, Nepal
}

\begin{abstract}
Background: Extra-articular fracture of proximal tibia is one of common injury. The study is randomized controlled trial in which individuals sustaining a fracture of the proximal metaphysis of the tibia will be operatively managed by one of two strategies. The first strategy involves fixation of the fracture with a reamed, interlocking intramedullary nail (Nail Group). The second treatment strategy involves percutaneous fixation of the fracture with a locking plate (Plate Group). Objective: To compare the functional outcome of intramedullary nailing versus percutaneous locked plating of extra-articular proximal tibial fractures in adults in terms of procedure time, time to achieve union, functional outcome, blood loss, cost of treatment, complication if any. Methods: It is randomised controlled trial study. The patients were randomized into two groups, each of size 60: Group A (IMIL group) Group B (Locking Plate group). During procedure patients were evaluated for blood loss, procedure time or any complications. Immediate post operative complications were taken into account and post operative radiological parameters measured. Results: A total of 120 patients (75 male and 45 female) were included in the study. Fifty five patients were less than 25 years age group followed by 30 patients between 25-40 yrs, 25 patients less than 25 age group and 10 patients more than 55 years. The average blood loss is $95 \mathrm{ml}$ in IMIL group and $105 \mathrm{ml}$ in locked plate group. Conclusion: IMIL is more expensive than percutaneous locked plates IMIL came out as a shorter surgery with little blood loss however at the same time much costlier to locked plating.
\end{abstract}

Keywords: Intamedullary nailing, locking plate, tibial fractures.

\footnotetext{
Address for correspondence

Dr.Pashupati Chaudhary

Additional Professor

Department of Orthopaedics

B.P. Koirala Institute of Health Sciences, Dharan

Email: chaudharypashupati@yahoo.com
} 


\section{Introduction}

Extra-articular fracture of proximal tibia is one of common injury accounting for $5-11 \%$ of all tibial shaft fractures often result from high-velocity trauma. They lead to complex tissue injuries involving bone and surrounding soft tissues. Various treatment options have been described for extra-articular fractures of proximal tibia in the literature; each has its own advantages and disadvantages ${ }^{1}$. Options include intramedullary implant, half-pin external fixation, hybrid or thin-wire external fixation, plate fixation, or a combination of these techniques.

Conservative management of these fractures has often resulted in malunion, non-union, rotational deformity, or stiffness of adjacent joints, so there has been a shift towards operative management of these fractures in recent times. However, the optimal method of surgically treating these fractures remains debatable ${ }^{2}$.

In recent years, closed reduction and minimally invasive plating and multidirectional locked intramedullary nailing have both become widely used treatment modalities for proximal and distal tibial metaphyseal fractures $^{3}$. The surgical goals for treating extra-articular proximal tibial fractures are to restore articular congruity, the mechanical axis, and knee motion while avoiding softtissue complications.
Due to the paucity of the relevant literature and the lack of conclusive evidence to guide the selection of treatment options in such cases, we designed this randomized controlled study (RCT) in order to compare the plating and nailing options in proximal tibia extra-articular fractures.

The objective of this study is to compare outcome of intramedullary nailing versus percutaneous locked plating of extra-articular proximal tibial fracture in terms of operative time, duration of hospital stay, Cost of treatment, Union time, Complications if any (malunion rate, infection rate, non-union).

\section{Methods}

It is randomised controlled trial study. Randamization was done using excel random number generation technique into two groups, each of size 60,Group A:- closed extra-articular proximal tibial fractures treated with intramedullary nailing,group B:- closed extra-articular proximal tibial fractures treated with percutaneous locked plating. The patients were randomized into two groups, each of size 60: Group A (IMIL group) Group $B$ (Locking Plate group) During procedure patients were evaluated for blood loss, procedure time or any complications. Immediate post operative complications were taken into account and post operative radiological parameters measured. Patients were reviewed after 2 weeks (for pin tract 
infection, early complications). At 6 weeks, 12 weeks and 24 weeks, the patient was evaluated for pain, range of motion, evidence of union, complications, subjective improvement using Quick DASH questionnaire and radiological parameters. The subjects will be enrolled after informed consent. The relevant information about demographic variables like age, sex, address, occupation; mode of injury, duration of injury, operative procedure, date of surgery and post-operative findings were recorded in a semi-structured proforma. The proforma was filled by the on duty residents of orthopaedics.

\section{Results}

A total of 120 patients (75 male and 45 female) were included in the study. Fifty five patients were less than 25 years age group followed by 30 patients between 25-40 yrs, 25 patients less than 25 age group and 10 patients more than 55 years. Road traffic accident is commonnest mode of injury followed by fall from height. The average blood loss is $95 \mathrm{ml}$ in IMIL group and $105 \mathrm{ml}$ in locked plate group. The procedure time is 60 mins as comprared to 70 mins in plate group.

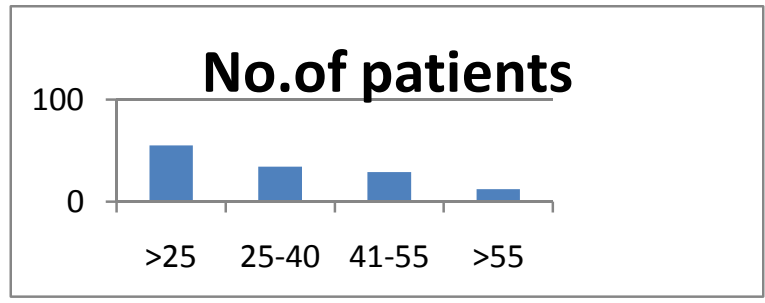

Figure 1: Number of patients

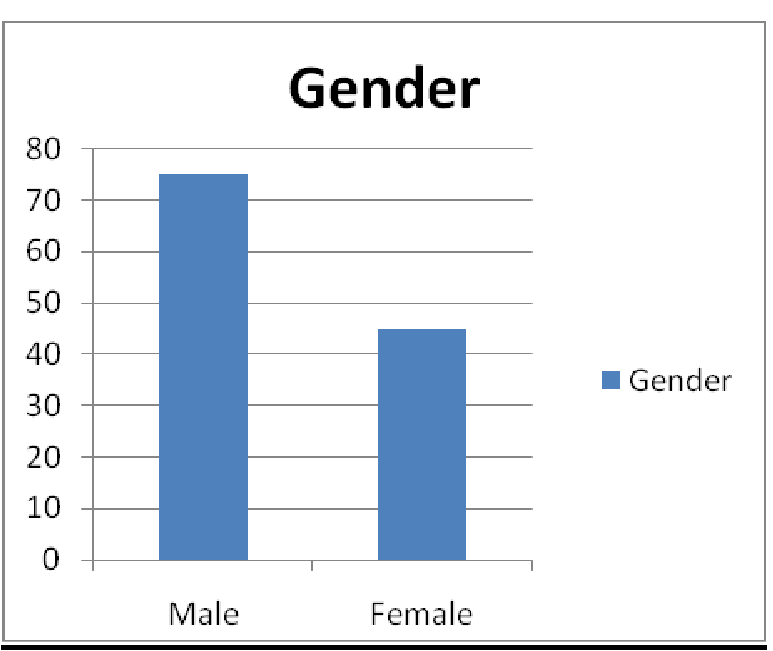

Figure 2: Gender

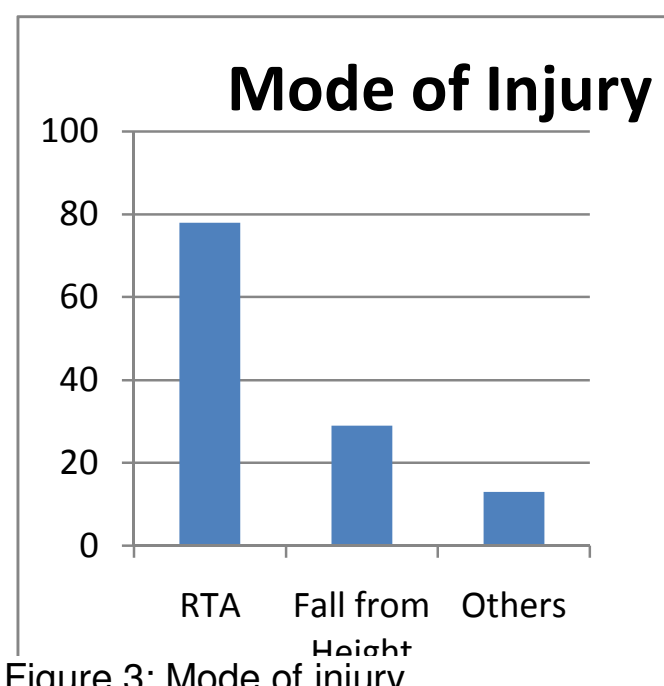

Figure 3: Mode of injury 


\section{Discussion}

Data allowing a comparison of tibial nail and minimally invasive plating for extra-articular proximal tibial fractures are scarce. The primary goal of this prospective study was to compare the results of tibial nailing and minimally invasive plating from various aspects.

A total of 120 patients (75 male and 45 female) were included in the study. 55 patients were less than 25 years age group followed by 30 patients between 25-40 yrs, 25 patients less than 25 age group and 10 patients more than 55 years. Road traffic accident is commonest mode of injury followed by fall from height. The average blood loss is $95 \mathrm{ml}$ in IMIL group and $105 \mathrm{ml}$ in locked plate group. The procedure time is 60 mins as comprared to 70 mins in plate group.

In the present study, patients in the IMIL group had a significantly shorter length of hospital stay compared with those in the plating group $(p<0.05)$ because of the smaller incision made during closed nailing, meaning that IMIL results in less of an economic burden and a lower cost of healthcare to society than Plating group.

Although early weight-bearing is inherently associated with a load-sharing device such as an IMIL, the literature does not accurately predict an accepted time at which full weightbearing should be initiated with either procedure. Various studies have often stated that weight-bearing should be initiated when it can be tolerated by the patient. In previous studies of extra-articular proximal, tibial fractures treated with IMIL, full weight-bearing was initiated at various times ranging from 0 to 16 weeks, depending on the fracture location, fracture pattern, and surgeon's preference. Similarly, in extra-articular proximal tibial fractures treated with plating, time to full weight-bearing has ranged from 6 to 13 weeks for the same reasons. In our study, the time required before full weightbearing, which was done only after complete radiological union, was significantly less in the IMIL group (14 weeks) as compared to the plating group (16 weeks). Although these times are longer than those stated in previously published reports, we started full weight-bearing only after complete clinical and radiological fracture union. That being said, we started passive and active assisted movements early- from day 2, progressing later to partial weight-bearing. Hence, we found no significant differences in range of motion of the knee between the groups.

Reported infection rates range from $1.67 \%$ in nailing patients and from $3.32 \%$ in plating patients. But in the study by Lindvell et al. the authors reported significantly higher infection rates: $28 \%$ in the nailing group and $24 \%$ in the plating group. The most probable reason for this is the higher proportion (42.8\%) of 
patients with open fractures in their study. In the systemic review by Bhandari et al., the infection rates were $2.5 \%$ in the nailing group and $14 \%$ in the plating group. The infection rates in our series were $5.3 \%$ in the IMN group and $8 \%$ in the PTP group ( $p=0.738)$.

When union rates after the initial fixation were analyzed in our study, it was found that the union rate in the IMIL group was higher than plating group. The high union rates observed in our series are consistent with those stated in various published reports, which range from 91 to $100 \%$. Our results were, however, higher than seen in a study performed by Lindvell et al. where the authors noted union rates of $77 \%$ in the IMN group and $94 \%$ in the PTP group. We believe that this difference in union rates arose because open fractures were excluded from our series, not because of the type of procedure performed. The locked nail technique demonstrated advantages in terms of the operation time, hospital stay, early full weight-bearing, and time required for bony union.

We concluded from our study that intramedullary nail is superior to minimally invasive plating in terms of brevity of hospital stay and speed of union along with early full weight-bearing, but there was no clear advantage of either technique in terms of operative time, infection rate, range of motion of the knee, and rates of malunion and nonunion. Both implants yielded promising results with extra-articular proximal tibial fractures and provided rigid fixation that prevented secondary fracture collapse.

\section{Conclusion}

IMIL is more expensive than percutaneous locked plates. IMIL came out as a shorter surgery with little blood loss however at the same time much costlier to locked plating.

\section{References}

1. Brad AP, Bhandari M, Schemitsch E. Tibia and fibula fractures: Principles of management. In: Rockwood and Green's Fractures in Adults. $7^{\text {th }}$ ed. Memphis: Lippincott Williams and Wilkins. 2010: 1867-75.

2. Nikolaou VS, Tan HB, Haidukewych G. Proximal tibial fractures: Early experience using polyaxial locking plate technology. Int Orthop. 2011; 35(8):1215-1221.

3. Hak DJ. Intramedullary Nailing of Proximal Third Tibial Fractures: Techniques to Improve Reduction. Orthopedics.2011; 34(7):532-35.

4. Rudloff MI. Fractures of the lower extremity: Tibial shaft: Treatment. In: Campbells Operative Orthopaedics. $12^{\text {th }}$ ed. Memphis (Tennessee): Mosby Elsevier. 2013; 2644-68.

5. Attal $R$, Hansen $M$, Kirjavainen $M$ et al. A multicentric case series of tibia 
fractures treated with the Expert Tibia Nail (ETN). Arch Orthop Trauma Surg. 2012; 132(7):975-84.

6. Attal $R$, Muller $M$, Hansen $M$ et al. Treatment of tibia fractures with the expert tibia nail- results of a prospective multicenter study. J Bone Joint Surg Br. 2009; 91-B no. SUPP । 10.

7. Hansen M, El Attal R, Blum $J$ et al. Intramedullary nailing of the tibia with the expert tibia nail. Oper Orthop Traumatol. 2009; 21(6):620-35.

8. Trlica J, Dedek T, Smejkal Ket al. Expert Tibial Nail (ETN) for treatment of diaphyseal tibial fractures in current and extended indications: technique and clinical results. Acta Chir Orthop Traumatol Cech. 2010; 77(3):235-41.

9. Li Y, Liu L, Tang $X$ et al. Comparison of low, multidirectional nailing and plating in the treatment of distal tibial metadia physeal fractures. International Orthopaedics (SICOT). 2012; 36:145762.

10. Kim JW, Oh C, Oh JK. Biomechanical analysis of operative methods in treatment of extraarticular fracture of the proximal tibia. Bone Joint J.2013; 95-B no. SUPP 1615

11. Bhandari $\mathrm{M}$, Audige $\mathrm{L}$, Ellis $\mathrm{T}$, et al. Operative treatment of extra-articular proximal tibial fractures. $J$ Orthop Trauma. 2003; 17(8):591-95. 